\title{
EMBARAZO ECTÓPICO BILATERAL
}

Jorge Alfonso Jerez López MD*, Luis Alejandro Zárate Rojas MD**, Johana Navarro Mejía MD***

\section{Resumen}

Paciente primigestante en el primer trimestre del embarazo que consulta a urgencias por dolor abdominal y síncope. Fue estudiada en ginecología y por los hallazgos imagenológicos sugirieron embarazo ectópico derecho. Se realizó laparotomía encontrando dilatación tubárica bilateral, motivo por el cual se practicó salpingectomía bilateral. El estudio patológico demostró embarazo ectópico bilateral al encontrar vellosidades coriales en ambas luces tubáricas.

Palabras clave: embarazo ectópico bilateral, salpingitis, endometriosis, anticonceptivos.

\section{BILATERAL ECTOPIC PREGNANCY}

\begin{abstract}
A nulliparous woman in the first trimester of pregnancy presented with abdominal pain and syncope to the emergency room. She was studied in the gynecology service and a pelvic ultrasound suggested a right ectopic pregnancy. She underwent a laparotomy which disclosed a bilateral tubal dilation. A bilateral salpingectomy was performed. Histology confirmed a synchronious bilateral ectopic pregnancy by demonstrating chorionic villi in both tubes.
\end{abstract}

Key W'ords: bilateral ectopic pregnancy, salpingitis, endometriosis, contraceptives.

\section{Introducción}

Se define como embarazo ectópico a la implantación del embrión por fuera del cuerpo uterino, encontrándose en la práctica entre 95 y $98 \%$ de los casos con localización tubárica y menor posibilidad en ovario y cavidad abdominal. La incidencia varía entre uno por 32 y uno por 300 nacidos vivos, ${ }^{1}$ y corresponden al 1 a $2 \%$ del total de las concepciones. ${ }^{2}$ Se ha encontrado una mayor frecuencia en pacientes de nivel socioeconómico bajo, raza negra y gestación en edad materna avanzada, según varios autores. ${ }^{1}$ Se han descrito factores de riesgo tubáricos, dentro de los que se encuentran anormalidades congénitas, neoplasias, infecciones, endometriosis, esterilización o reconstrucción tubárica y salpingitis crónica, así como otros extratubáricos como
Fecha recibido: julio 28 de $201 \mathrm{I}$ - Fecha aceptado: agosto 8 de $201 \mathrm{I}$

* Residente Il de Patología, Fundación Universitaria de Ciencias de la Salud, Bogotá DC. Colombia.
** Residente I de Patologia, Fundación Universitaria de Ciencias de la Salud. Bogotá DC. Colombia.

*** Médico patólogo. Instructor asistente, Fundación Universitaria de Ciencias de la Salud. Bogotá DC. Colombia. 
ovulación disfuncional, dispositivos intrauterinos y terapia anticonceptiva, cirugía abdominal, reproducción asistida y tabaquismo. ${ }^{1}$ Cerca del $50 \%$ de los embarazos ectópicos tubáricos se encuentran en la ampolla, $20 \%$ en el istmo, $12 \%$ en la fimbria y alrededor del $10 \%$ intersticial. Por lo regular es unilateral aunque se han descrito pocos casos de presentación bilateral, cuya incidencia varía de uno en 725 a uno en 1.580 del total de embarazos ectópicos. ${ }^{3,4}$ El primer caso fue publicado en $1918^{4} \mathrm{y}$ desde entonces se han reportado más de 200 casos en la literatura mundial. En los embarazos bilaterales los embriones pueden tener la misma o diferente edad gestacional. ${ }^{5} \mathrm{El}$ aumento en la incidencia de estos casos se ha relacionado con la administración de agentes ovulatorios. ${ }^{6}$ Esta patología requiere un estudio precoz con ayudas diagnósticas como ultrasonografía y niveles séricos de fracción beta de gonadotrofina coriónica, por el alto porcentaje de complicaciones.

\section{Presentación del caso}

Paciente de 30 años primigestante con embarazo de 7.3 semanas por fecha de última menstruación, quien asiste a consulta por clínica de tres días de evolución consistente en dolor tipo cólico en región hipogástrica.

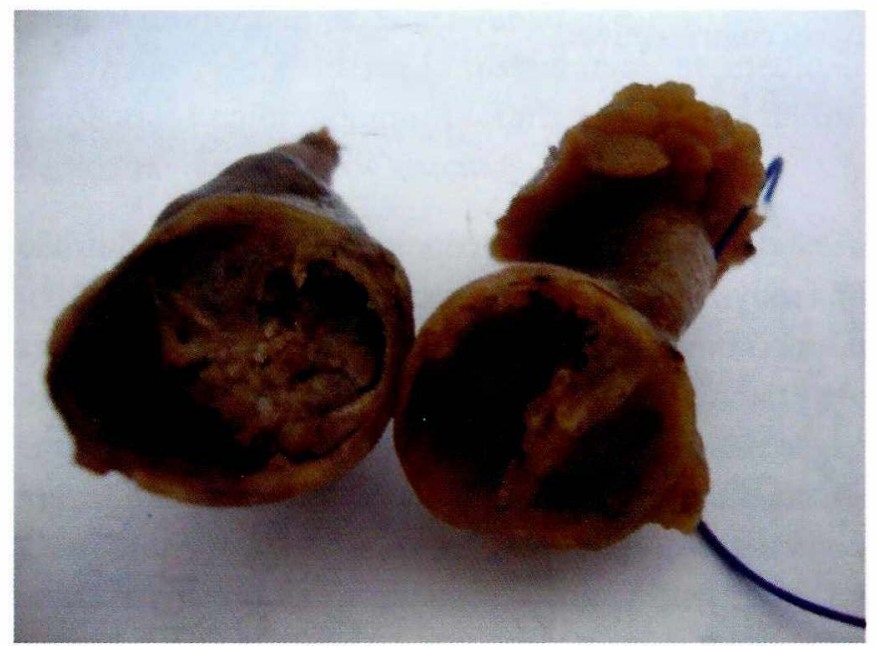

Figura I. Trompa uterina derecha.
Niega sangrado u otra sintomatología y refirió haber presentado episodio sincopal sin pérdida de la conciencia. No hay antecedentes relevantes, G1P0. Al examen físico hay dolor en hipogastrio sin signos de irritación peritoneal, examen ginecológico sin alteraciones. Se realiza ecografía obstétrica encontrando útero de tamaño, forma y contornos usuales, endometrio de aspecto habitual, grosor de $11 \mathrm{~mm}$ sin observar saco gestacional, ovarios de tamaño y ecogenicidad normales. Hay imágenes sugestivas de embarazo ectópico roto en trompa uterina derecha, por lo que se considera realizar laparotomía exploratoria. Se encontró hemoperitoneo, embarazo tubárico derecho roto y hallazgos macroscópicos de hematosálpinx con deformidad importante de trompa izquierda. El útero y los ovarios no mostraron alteraciones.

En el servicio de patología se reciben los especímenes correspondientes a dos segmentos de trompas uterinas, derecha e izquierda, ambas de color pardo violáceo que miden $7 \times 2 \mathrm{~cm}$, con luces dilatadas ocupadas por material de aspecto hemorrágico (Figuras 1 y 2). Al estudio microscópico se observaron dos secciones de trompas uterinas con edema, congestión vascular y hemorragia en la luz con vellosidades coriales inmaduras (Figuras 3 y 4).

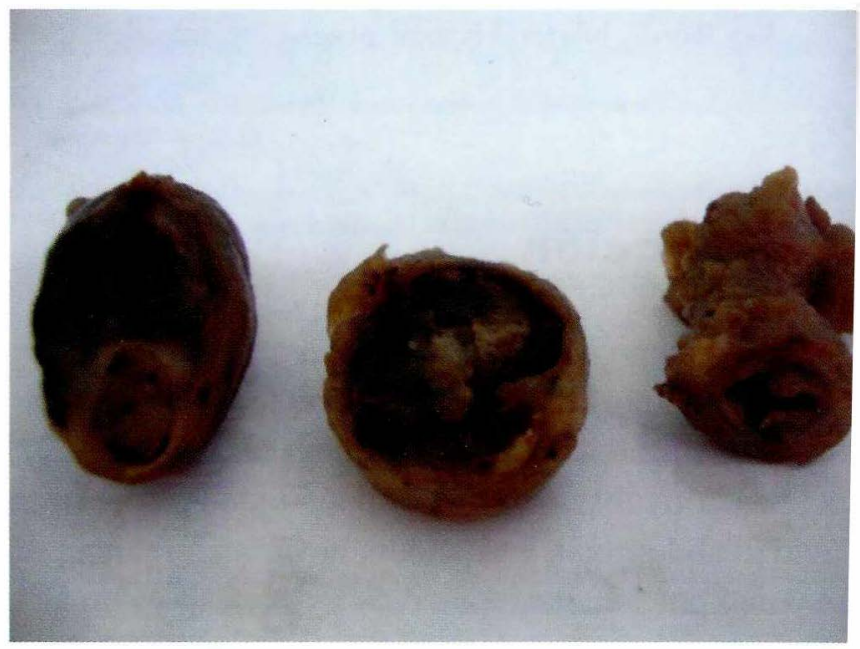

Figura 2. Trompa uterina izquierda. 


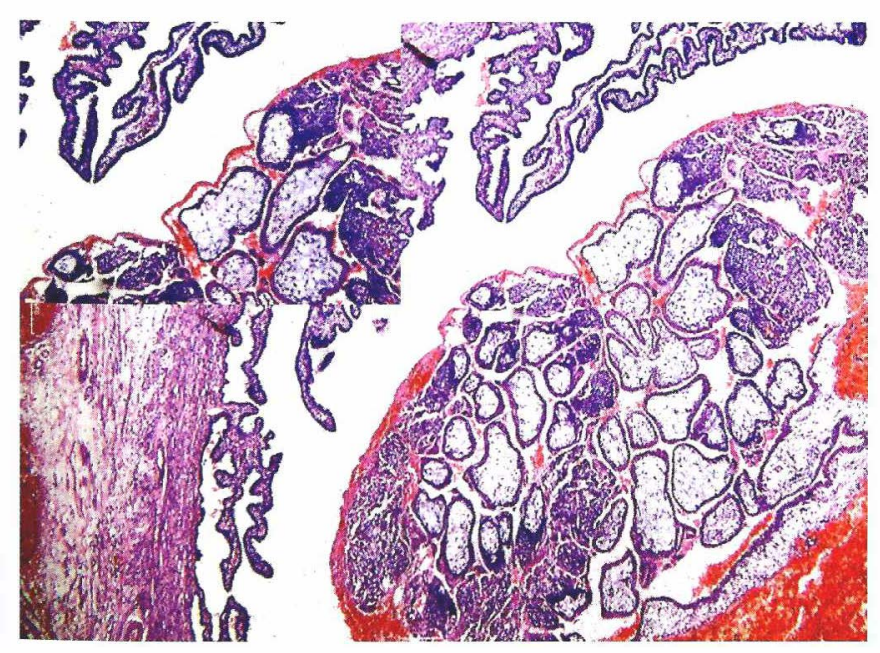

Figura 3: Trompa uterina derecha.

\section{Discusión}

El diagnóstico definitivo del embarazo ectópico uni o bilateral se obtiene solo tras visualizar en los cortes histológicos vellosidades coriónicas, ocupando la luz de las trompas de Falopio, trofoblasto en la pared, presencia de sincitiotrofoblasto, lámina propia que muestra cambios por decidualización o la identificación microscópica del embrión. Desde el punto de vista epidemiológico es un hecho infrecuente. ${ }^{4} \mathrm{~A}$ menudo la sospecha diagnóstica se establece en el intraoperatorio, aunque a veces no es claro por qué el compromiso tubárico puede ser asimétrico. ${ }^{4}$

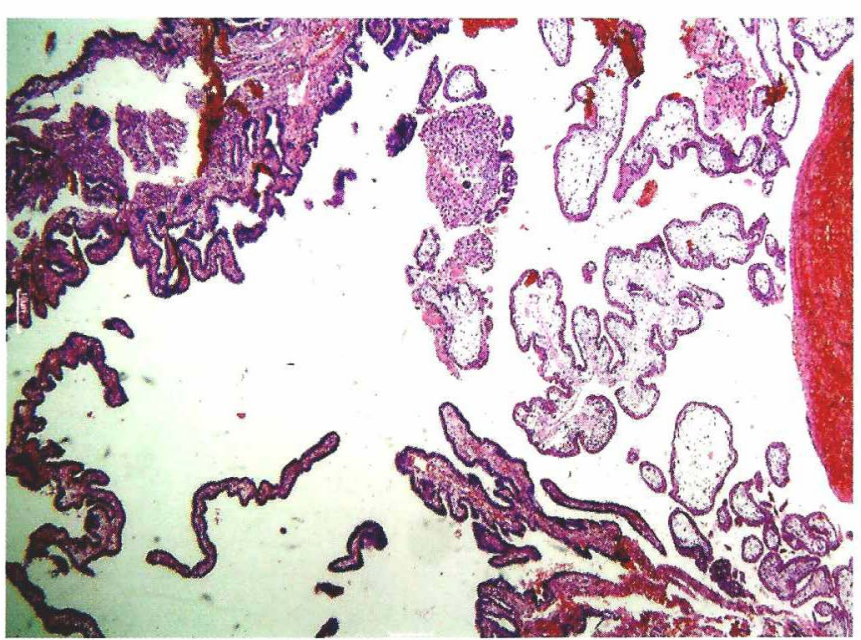

Figura 4. Trompa uterina izquierda.

\section{Referencias}

1. Ectopic Pregnancy, in: Haynes \& Taylor. Obstetrical and Gynecological Pathology; Churchill Livingstone. 2003;1045-69.

2. Female Reproductive System, in: Gattuso, Reddy, Spitz, Haber, Differential Diagnosis in surgical Pathology. Second edition. 2010;690-1.

3. Robertson WB. Bilateral Fallopian tube pregnancy. Fertility and sterility. 1980;33:86-7.

4. De Graaf FL, Demetroulis C. Bilateral tubal ectopic pregnancy diagnostic pitfalls. British Journal of Clinical Practice. 1997;51:56-8.

5. Hakim-Elahi E. Unruptured bilateral tubal pregnancy: report of case. Obstetrics and Gynecology. 1965;26:763-6.

6. Norris S. Bilateral simultaneous tubal pregnancy. Can Med Assoc J. 1953; 68:379-81. 